\title{
A report of nine cases and review of the literature of infertile men carrying balanced translocations involving chromosome 5
}

\author{
Hong-Guo Zhang, Rui-Xue Wang, Yuan Pan, Han Zhang, Lei-Lei Li, Hai-Bo Zhu and Rui-Zhi Liu*
}

\begin{abstract}
Background: Balanced translocations may cause the loss of genetic material at the breakpoints and may result in failure of spermatogenesis. However, carriers of reciprocal translocation may naturally conceive. Genetic counseling of male carriers of translocations remains challenging. This study explores the clinical features of carriers of chromosome 5 translocations, enabling informed genetic counseling of these patients.

Results: Of 82 translocation carriers, 9 (11\%) were carriers of a chromosome 5 translocation. One case had azoospermia, while three cases had experienced recurrent spontaneous abortions, two cases had each experienced stillbirth, and three cases produced a phenotypically normal child confirmed by amniocentesis. A literature review identified 106 patients who carried chromosome 5 translocations. The most common chromosome 5 translocation was $t(4,5)$, observed in 13 patients. Breakpoint at 5p15 was observed in 11 patients. All breakpoints at chromosome 5 were associated with gestational infertility.

Conclusion: In genetic counseling, physicians should consider chromosome 5 and its breakpoints. Carriers of chromosome 5 translocations may continue with natural conception or use assisted reproductive technologies, such as preimplantation genetic diagnosis.
\end{abstract}

Keywords: Male infertility, Chromosome 5, Balanced translocation, Breakpoint, Genetic counseling

\section{Background}

Known chromosomal alterations play a major role in perturbing male fertility [1]. Reciprocal chromosomal translocations are the most common structural rearrangement, with an incidence in infertile males up to ten times higher than in fertile men [2]. Balanced chromosomal translocations may cause the loss of genetic material at breakpoints and may result in failure of spermatogenesis [3]. Individuals affected by such translocations exhibit reproductive problems such as infertility, recurrent pregnancy loss, and malformed offspring $[4,5]$. These effects are related to the specific chromosomes and breakpoints involved in the translocation $[6,7]$. Some breakpoints can disrupt the structure of an important gene, leading to spermatogenic or maturation disorders, and male infertility [5]. Important genes associated with male infertility are located on

\footnotetext{
*Correspondence: Irz410@126.com

Center for Reproductive Medicine and Center for Prenatal Diagnosis, First Hospital, Jilin University, 71 Xinmin Street, Chaoyang District, Changchun,
} Jilin Province 130021, China chromosome 5. For example, Camk4 (encoding $\mathrm{Ca}^{2+} / \mathrm{cal}-$ modulin-dependent protein kinase IV) is located on chromosome 5q22.1, and is expressed in spermatids and associated with chromatin and nuclear matrix [8]. Disrupted CAMK4 expression may be associated with human male infertility [8]. In addition, the Spink13 gene (encoding serine protease inhibitor, Kazal-type 13), mapped on chromosome 5 at $5 \mathrm{q} 32$, was reported to be associated with sperm maturation [9]. The breakpoint of $5 \mathrm{p} 13$ was shown to be related to impaired spermatogenesis [10].

However, genetic counseling of male carriers of chromosomal translocations remains challenging. Preimplantation genetic diagnosis (PGD) is recommended for those exhibiting a balanced translocation. Microdissection testicular sperm extraction and in vitro fertilization accompanied by PGD increases the chance of these carriers fathering a healthy child [11, 12]. Clinical characteristics, including spontaneous abortion, do not differ between those couples who accept and those who decline PGD [13]. A systematic review showed there was 
Table 1 Karyotypes of chromosome 5 translocation carriers and their clinical features

\begin{tabular}{|c|c|c|c|}
\hline $\begin{array}{l}\text { Infertility } \\
\text { causes }\end{array}$ & Clinical findings & Karyotype & $\begin{array}{l}\text { Giemsa } \\
\text { banding } \\
\end{array}$ \\
\hline $\begin{array}{l}\text { Pregestational } \\
\text { infertility }\end{array}$ & Azoospermia & $46, X Y, t(5 ; 21)(q 13 ; p 12)$ & $\overline{\text { Figure } 1 \mathrm{a}}$ \\
\hline \multirow{8}{*}{$\begin{array}{l}\text { Gestational } \\
\text { infertility }\end{array}$} & \multirow{8}{*}{$\begin{array}{l}\text { Normal sperm } \\
\text { density; a history } \\
\text { of miscarriage, } \\
\text { or normal fertility }\end{array}$} & $46, X Y, t(4 ; 5)(q 31 ; p 15)$ & Figure $1 b$ \\
\hline & & $46, X Y, t(5 ; 11)(p 14 ; p 15)$ & Figure $1 \mathrm{c}$ \\
\hline & & $46, X Y, t(5 ; 13)(q 13 ; q 12)$ & Figure 1d \\
\hline & & $46, X Y, t(5 ; 18)(p 13 ; p 11)$ & Figure 1e \\
\hline & & $46, X Y, t(5 ; 18)(p 15 ; q 11.2)$ & Figure if \\
\hline & & $46, X Y, t(5 ; 20)(q 13 ; q 12)$ & Figure $1 \mathrm{~g}$ \\
\hline & & $46, X Y, t(5 ; 21)(p 13 ; q 22)$ & Figure $1 \mathrm{~h}$ \\
\hline & & $46, X Y, t(5 ; 22)(p 11 ; p 11)$ & Figure 1i \\
\hline
\end{tabular}

insufficient evidence that PGD improves the live birth rate in couples with repeated miscarriage and carrying a structural chromosome abnormality [14]. In addition, the live birth rate in patients refused PGD and choosing to conceive naturally was reported to be $37-63 \%$ for the first pregnancy, and then a cumulative rate of $65-83 \%$ [4]. Natural pregnancy success rates for couples in which the male carries a chromosomal translocation ranged from $30 \%$ to $70 \%$ [15]. This suggests that continued attempts to conceive naturally are a viable option for successful pregnancy, however, the relationship between clinical features and chromosome structural abnormality warrants further study.

The present study was established to explore the clinical features and translocation breakpoints in carriers of balanced translocations involving chromosome 5 . This paper also highlights the importance of genetic counseling for infertile men.

\section{Methods \\ Patients}

Between July 2010 and December 2016, 82 male carriers of chromosomal translocations who were experiencing infertility, or receiving counseling, were recruited from the outpatient's department at the Center for Reproductive Medicine, the First Hospital of Jilin University, Changchun, China. All patients underwent a thorough physical examination and semen analysis, and were required to complete a detailed questionnaire regarding their smoking habits, marital status, medical history, and working conditions. The study protocol was approved by the Ethics Committee of the First Hospital of Jilin University, and written informed consent was obtained from all participants.

\section{Semen analysis}

Semen analysis was performed according to procedures recommended by the World Health Organization guidelines. If no sperm was found, sperm was analyzed by sedimenting semen samples through centrifugation. Patients with oligozoospermia were diagnosed as a sperm count less than $15 \times 10^{6} / \mathrm{ml}$ in their last three semen samples (taken at intervals of 1-3 weeks). Azoospermia and oligozoospermia were defined as previously described [5]. All analyses were performed at the same laboratory, and all data were accessed from medical records. a

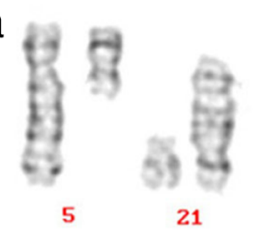

d

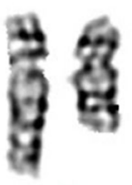

5

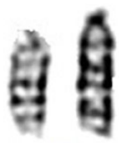

13

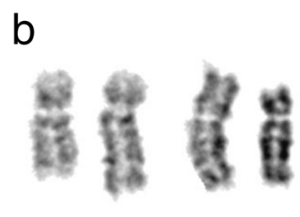

4

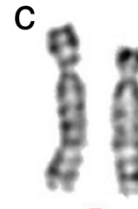

5

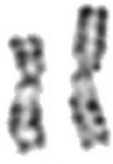

11

e

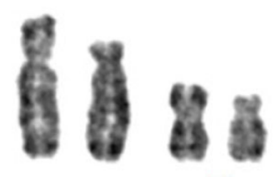

18

f

5

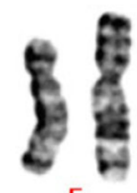

5

18

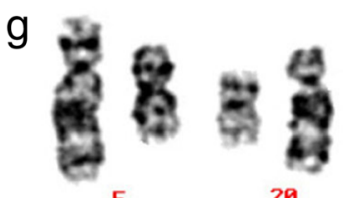

$\mathrm{h}$

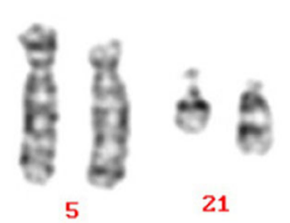

i

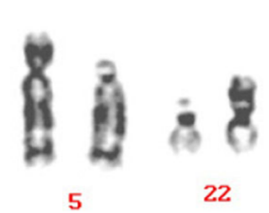

Fig. 1 G-banding karyotype of the nine cases identified as possessing chromosome 5 translocations. a: $t(5 ; 21)$, b: t( $(4 ; 5)$, c: $t(5 ; 1)$, d:t(5;13), e: $t(5 ; 18)(p 13 ; p 11), \mathbf{f}: t(5 ; 18)(p 15 ; q 11.2), \mathbf{g}: t(5 ; 20), \mathbf{h}: t(5 ; 21), \mathbf{i}: t(5 ; 22)$ 
Table 2 Breakpoints in chromosome 5 translocation carriers and clinical features

\begin{tabular}{|c|c|c|c|c|}
\hline Case & Karyotype & Breakpoints & Clinical findings & Reference \\
\hline 1 & $t(1 ; 5)$ & $1 \mathrm{p} 32 ; 5 \mathrm{q} 31$ & Severe oligoasthenoteratozoospermia & Peschka et al., 1999 [27] \\
\hline 2 & $t(1 ; 5)$ & $1 p 31.1 ; 5 q 33.3$ & Normozoospermia & Brugnon et al., 2006 [28] \\
\hline 3 & $t(1 ; 5)$ & $1 p 22 ; 5 q 11$ & Malformed/stillborn children & Meza-Espinoza et al., 2008 [29] \\
\hline 4 & $t(1 ; 5)$ & $1 q 36.1 ; 5 q 31$ & 2 miscarriage, PGD and 2 term delivery & Ikuma et al., 2015 [4] \\
\hline 5 & $t(1 ; 5)$ & $1 q 41 ; 5 q 33$ & Miscarriage and PGD & Kyu Lim et al., 2004 [30] \\
\hline 6 & $t(1 ; 5)$ & 1qter;5p14 & Recurrent miscarriage & Goud et al., 2009 [31] \\
\hline 7 & $t(2 ; 5)$ & $2 \mathrm{p} 25 ; 5 \mathrm{p} 12$ & Teratozoospermia, Habitual abortions & Vegetti et al., 2000 [32] \\
\hline 8 & $t(2 ; 5)$ & $2 \mathrm{p} 21 ; 5 \mathrm{p} 15$ & Recurrent spontaneous abortion & Gada Saxena et al., 2012 [33] \\
\hline 9 & $t(2 ; 5)$ & $2 \mathrm{p} 13 ; 5 \mathrm{p} 15$ & Recurrent fetal wastage & Fryns et al., 1998 [34] \\
\hline 10 & $t(2 ; 5)$ & $2 p 11 ; 5 q 15$ & Abortion & Templado et al., 1988 [35] \\
\hline 11 & $t(2 ; 5)$ & $2 p 11 ; 5 q 31$ & Recurrent abortion & Portnoï et al., 1988 [36] \\
\hline 12 & $t(2 ; 5)$ & $2 q 12 ; 5 q 35.3$ & Recurrent pregnancy loss & Kochhar et al., 2013 [22] \\
\hline 13 & $t(2 ; 5)$ & $2 q 13.1 ; 5 q 35.1$ & 6 miscarriage, PGD and 1 term delivery & Ikuma et al., 2015 [4] \\
\hline 14 & $t(3 ; 5)$ & $3 p 27 ; 5 p 14$ & 4 fetal losses & Adamoli et al., 1986 [37] \\
\hline 15 & $t(3 ; 5)$ & $3 q 13 ; 5 q 35$ & Repeated abortions & Venkateshwari et al., 2011 [21] \\
\hline 16 & $t(3 ; 5)$ & $3 q 26.2 ; 5 p 15.1$ & Miscarriage & Sugiura-Ogasawara et al., 2008 [38] \\
\hline 17 & $t(3 ; 5)$ & $3 q 27 ; 5 p 15$ & Normospermic, A boy 46,XY,t(3;5)pat & Vozdova et al., 2013 [11] \\
\hline 18 & $t(3 ; 5)$ & $3 q 28 ; 5 p 13$ & Recurrent spontaneous abortion & Gada Saxena et al., 2012 [33] \\
\hline 19 & $t(3 ; 5)$ & $3 q 29 ; 5 q 13$ & Multiple abortions & Castle et al., 1988 [39] \\
\hline 20 & $t(3 ; 5)$ & $3 q 29 ; 5 q 33.2$ & PGD & Findikli et al., 2003 [40] \\
\hline 21 & $t(4 ; 5)$ & $4 \mathrm{p} 15.2 ; 5 \mathrm{p} 12$ & Normozoospermia & Wiland et al., 2007 [41] \\
\hline 22 & $t(4 ; 5)$ & $4 p 15 ; 5 q 12$ & Oligozoospermia & Perrin et al., 2010 [42] \\
\hline 23 & $t(4 ; 5)$ & $4 p 14 ; 5 q 13.1$ & recurrent miscarriage & Pundir et al., 2016 [43] \\
\hline 24 & $t(4 ; 5)$ & $4 q 21 ; 5 p 15$ & Habitual miscarriage & Li et al., 2012 [23] \\
\hline 25 & $t(4 ; 5)$ & $4 q 21 ; 5 p 15$ & Recurrent spontaneous abortion & Zhang M et al., 2015 [44] \\
\hline 26 & $t(4 ; 5)$ & $4 q 21 ; 5 q 11.2$ & Severe oligoasthenoteratozoospermia & Peschka et al., 1999 [27] \\
\hline 27 & $t(4 ; 5)$ & $4 q 22 ; 5 q 35$ & 2 fetal losses & Adamoli et al., 1986 [37] \\
\hline 28 & $t(4 ; 5)$ & $4 q 25 ; 5 p 15.2$ & 4 abortions & Ghazaey et al., 2015 [45] \\
\hline 29 & $t(4 ; 5)$ & $4 q 31 ; 5 p 15$ & Recurrent spontaneous abortions & Zhang et al., 2011 [46] \\
\hline 30 & $t(4 ; 5)$ & $4 q 31 ; 5 q 13$ & normozoospermia & Huang et al., 2007 [47] \\
\hline 31 & $t(4 ; 5)$ & $4 q 32 ; 5 q 14$ & Oligoasthenoteratozoospermia & Dohle et al., 2002 [48] \\
\hline 32 & $t(4 ; 5)$ & $4 q 32 ; 5 q 14$ & Miscarriage & Dul et al., 2012 [49] \\
\hline 33 & $t(4 ; 5)$ & $4 q 35 ; 5 p 15$ & Recurrent miscarriages & Dutta et al., 2011 [50] \\
\hline 34 & $t(5 ; 6)$ & $5 p 15.3 ; 6 q 13$ & recurrent abortion & Kiss et al., 2009 [51] \\
\hline 35 & $t(5 ; 6)$ & $5 p 13.3 ; 6 q 27$ & Recurrent spontaneous abortion & Gada Saxena et al., 2012 [33] \\
\hline 36 & $t(5 ; 6)$ & $5 q 21 ; 6 q 33$ & Recurrent fetal wastage & Fryns et al., 1998 [34] \\
\hline 37 & $t(5 ; 6)$ & $5 q 33.1 ; 6 p 11.2$ & Miscarriage & Sugiura-Ogasawara et al., 2008 [38] \\
\hline 38 & $t(5 ; 6)$ & $5 q 35 ; 6 p 21.3$ & PGD & Ko et al., 2010 [52] \\
\hline 39 & $\mathrm{t}(5 ; 7)$ & $5 p 15.2 ; 7 p 14$ & Recurrent spontaneous abortion & Gada Saxena et al., 2012 [33] \\
\hline 40 & $t(5 ; 7)$ & $5 p 13 ; 7 p 15$ & Recurrent pregnancy loss & Kochhar et al., 2013 [22] \\
\hline 41 & $t(5 ; 7)$ & $5 p 13 ; 7 p 15$ & Spontaneous abortion & Stephenson et al., 2006 [53] \\
\hline 42 & $\mathrm{t}(5 ; 7)$ & $5 p 11 ; 7 q 11$ & 8 abortions & Al-Hussain et al., 2000 [54] \\
\hline 43 & $\mathrm{t}(5 ; 7)$ & $5 q 13 ; 7 p 15.1$ & 2 miscarriages & Estop et al., 1995 [55] \\
\hline 44 & $\mathrm{t}(5 ; 7)$ & $5 q 21 ; 7 q 32$ & Normozoospermia & Cifuentes et al., 1999 [56] \\
\hline
\end{tabular}


Table 2 Breakpoints in chromosome 5 translocation carriers and clinical features (Continued)

\begin{tabular}{|c|c|c|c|c|}
\hline Case & Karyotype & Breakpoints & Clinical findings & Reference \\
\hline 45 & $t(5 ; 7)$ & $5 q 33 ; 7 q 22$ & Miscarriage and PGD & Kyu Lim et al., 2004 [30] \\
\hline 46 & $t(5 ; 8)$ & $5 p 14 ; 8 q 22$ & Asthenozoospermia & Godo et al., 2013 [7] \\
\hline 47 & $t(5 ; 8)$ & $5 q 22 ; 8 q 24.1$ & Oligoasthenoteratozoospermia & Meschede et al., 1998 [57] \\
\hline 48 & $t(5 ; 8)$ & $5 q 22.1 ; 8 q 23.2$ & $P G D$ & Ko et al., 2010 [52] \\
\hline 49 & $t(5 ; 8)$ & $5 q 23.1 ; 8 p 23.2$ & 4 miscarriage, 1 term delivery & Ikuma et al., 2015 [4] \\
\hline 50 & $t(5 ; 8)$ & $5 q 33.3 ; 8 q 11.21$ & Recurrent miscarriage & Pundir et al., 2016 [43] \\
\hline 51 & $t(5 ; 8)$ & $5 q 33 ; 8 q 13$ & Normozoospermia & Blanco et al., 1998 [58] \\
\hline 52 & $t(5 ; 8)$ & $5 q 33 ; 8 q 13$ & Normozoospermia & Estop et al., 2000 [59] \\
\hline 53 & $t(5 ; 8)$ & $5 q 33 ; 8 q 13$ & Normozoospermia & Godo et al., 2013 [7] \\
\hline 54 & $t(5 ; 8)$ & $5 q 33 ; 8 q 13$ & Normozoospermia & Anton et al., 2008 [60] \\
\hline 55 & $t(5 ; 8)$ & $5 q 35.1 ; 8 p 11.2$ & Astenozoospermia & Anton et al., 2008 [60] \\
\hline 56 & $t(5 ; 8)$ & $5 q 35.3 ; 8 q 22.1$ & Recurrent fetal wastage & Fryns et al., 1998 [34] \\
\hline 57 & $\mathrm{t}(5 ; 9)$ & $5 p 15.1 ; 9 q 22.1$ & Normospermic, Primary infertility & Vozdova et al., 2013 [11] \\
\hline 58 & $t(5 ; 9)$ & $5 p 13 ; 9 q 22$ & PGD & Zhang et al., 2014 [61] \\
\hline 59 & $\mathrm{t}(5 ; 9)$ & $5 q 10 ; 9 q 10$ & Recurrent spontaneous abortions & Rouen et al., 2017 [62] \\
\hline 60 & $t(5 ; 9)$ & $5 q 21 ; 9 q 34$ & 2 fetal losses & Adamoli et al., 1986 [37] \\
\hline 61 & $\mathrm{t}(5 ; 9)$ & $5 q 23.2 ; 9 q 22.3$ & Spontaneous abortion & Stephenson et al., 2006 [53] \\
\hline 65 & $t(5 ; 9)$ & $5 q 23.3 ; 9 p 24$ & Recurrent miscarriage & lyer et al., 2007 [63] \\
\hline 63 & $t(5 ; 10)$ & 5p13.3;10p12.2 & PGD & Ko et al., 2010 [52] \\
\hline 64 & $\mathrm{t}(5 ; 10)$ & $5 q 22 ; 10 q 11.2$ & PGD & Ko et al., 2010 [52] \\
\hline 65 & $\mathrm{t}(5 ; 10)$ & $5 q 22 ; 10 q 22$ & Miscarriage & Sugiura-Ogasawara et al., 2008 [38] \\
\hline 66 & $t(5 ; 10)$ & $5 q 34 ; 10 p 12.1$ & Recurrent spontaneous abortions & Rouen et al., 2017 [62] \\
\hline 67 & $\mathrm{t}(5 ; 10)$ & $5 q 35 ; 10 q 22$ & Spontaneous abortions & Bourrouillou et al., 1986 [64] \\
\hline 68 & $\mathrm{t}(5 ; 10)$ & $5 q 35 ; 10 q 24$ & Recurrent miscarriage & Goud et al., 2009 [31] \\
\hline 69 & $t(5 ; 11)$ & $5 p 14 ; 11 p 15$ & Normozoospermia & Zhang HG et al., 2015 [5] \\
\hline 70 & $t(5 ; 12)$ & $5 p 15.1 ; 12 p 12.2$ & Spontaneous abortion & Stephenson et al., 2006 [53] \\
\hline 71 & $\mathrm{t}(5 ; 12)$ & $5 p 15.1 ; 12 q 21$ & Infertility & Ravel et al., 2006 [65] \\
\hline 72 & $t(5 ; 12)$ & $5 p 14 ; 12 q 15$ & Recurrent spontaneous abortion & Gada Saxena et al., 2012 [33] \\
\hline 73 & $t(5 ; 12)$ & $5 q 11 ; 12 p 13$ & 10 abortions & Al-Hussain et al., 2000 [54] \\
\hline 74 & $\mathrm{t}(5 ; 12)$ & $5 q 13 ; 12 q 13$ & Recurrent spontaneous abortions & Rouen et al., 2017 [62] \\
\hline 75 & $t(5 ; 12)$ & $5 q 35.1 ; 12 q 24.1$ & Repeated miscarriage & Goddijn et al., 2004 [66] \\
\hline 76 & $t(5 ; 13)$ & $5 p 13 ; 13 q 34$ & Neonatal death & Zhang et al., 2006 [67] \\
\hline 77 & $t(5 ; 13)$ & $5 q 11 ; 13 q 33$ & 3 spontaneous abortions & Pellestor et al., 1989 [68] \\
\hline 78 & $t(5 ; 13)$ & $5 q 13 ; 13 q 12$ & Normozoospermia & Zhang HG et al., 2015 [5] \\
\hline 79 & $t(5 ; 13)$ & $5 q 15 ; 13 p 12$ & Oligozoospermia & Matsuda et al., 1992 [69] \\
\hline 80 & $t(5 ; 13)$ & $5 q 21 ; 13 q 12.1$ & 2 miscarriage, no conception & Ikuma et al., 2015 [4] \\
\hline 81 & $t(5 ; 13)$ & $5 q 33 ; 13 q 12$ & Infertility & Mikelsaar et al., 2012 [20] \\
\hline 82 & $t(5 ; 13)$ & $5 q 34 ; 13 q 33$ & Recurrent miscarriage & lyer et al., 2007 [63] \\
\hline 83 & $t(5 ; 14)$ & $5 p 13 ; 14 q 11.2$ & PGD & Zhang et al., 2014 [61] \\
\hline 84 & $t(5 ; 14)$ & $5 p 13 ; 14 q 23$ & Spontaneous abortions & Bourrouillou et al., 1986 [64] \\
\hline 85 & $t(5 ; 14)$ & $5 q 11.2 ; 14 q 32.1$ & Spontaneous abortion & Stephenson et al., 2006 [53] \\
\hline 86 & $t(5 ; 15)$ & $5 p 15.2 ; 15 q 21.1$ & PGD & Ko et al., 2010 [52] \\
\hline 87 & $t(5 ; 15)$ & $5 p 13.3 ; 15 q 15.3$ & PGD & Ko et al., 2010 [52] \\
\hline 88 & $\mathrm{t}(5 ; 15)$ & $5 q 35 ; 15 q 22$ & Pregnancy of PGD & Escudero et al., 2003 [70] \\
\hline
\end{tabular}


Table 2 Breakpoints in chromosome 5 translocation carriers and clinical features (Continued)

\begin{tabular}{|c|c|c|c|c|}
\hline Case & Karyotype & Breakpoints & Clinical findings & Reference \\
\hline 89 & $\mathrm{t}(5 ; 15)$ & $5 q 35 ; 15 q 26.2$ & Abnormal semen, 2 IVF-ET & Vozdova et al., 2013 [11] \\
\hline 90 & $t(5 ; 16)$ & $5 q 13 ; 16 p 13.1$ & Normozoospermia & Haapaniemi Kouru et al., 2017 [71] \\
\hline 91 & $\mathrm{t}(5 ; 16)$ & $5 q 33 ; 16 p 13$ & Recurrent pregnancy loss & Kochhar et al., 2013 [22] \\
\hline 92 & $\mathrm{t}(5 ; 16)$ & $5 q 33.3 ; 16 p 13.3$ & Recurrent miscarriages & Dutta et al., 2011 [50] \\
\hline 93 & $\mathrm{t}(5 ; 17)$ & $5 q 13.2 ; 17 q 21.2$ & infertility & Mau et al., 1997 [72] \\
\hline 94 & $t(5 ; 17)$ & $5 q 31 ; 17 p 13$ & Normozoospermia & Anton et al., 2008 [60] \\
\hline 95 & $t(5 ; 17)$ & $5 q 33.1 ; 17 q 25.3$ & Repeated miscarriage & Goddijn et al., 2004 [66] \\
\hline 96 & $\mathrm{t}(5 ; 18)$ & $5 p 15 ; 18 q 11.2$ & Spontaneous abortion & Zhang HG et al., 2015 [5] \\
\hline 97 & $\mathrm{t}(5 ; 18)$ & $5 p 15 ; 18 q 21$ & Malformed children & Balkan et al., 1983 [73] \\
\hline 98 & $\mathrm{t}(5 ; 18)$ & $5 q 15 ; 18 q 22$ & Spontaneous abortions & Soh et al., 1984 [74] \\
\hline 99 & $t(5 ; 18)$ & $5 q 15 ; 18 q 23$ & 2 fetal loss & Smith et al., 1990 [75] \\
\hline 100 & $\mathrm{t}(5 ; 18)$ & $5 q 31.1 ; 18 q 21.1$ & PGD & Ko et al., 2010 [52] \\
\hline 101 & $t(5 ; 19)$ & $5 q 15 ; 19 p 12$ & Normospermic, A boy $46, X Y, t(5 ; 19)$ pat & Vozdova et al., 2013 [11] \\
\hline 102 & $\mathrm{t}(5 ; 20)$ & $5 q 22 ; 20 p 13$ & Asthenozoospermia, Habitual abortions & Vegetti et al., 2000 [32] \\
\hline 103 & $\mathrm{t}(5 ; 20)$ & $5 q 13 ; 20 q 12$ & Normozoospermia & Zhang HG et al., 2015 [5] \\
\hline 104 & $t(5 ; 20)$ & $5 q 22 ; 20 p 12$ & Recurrent fetal wastage & Fryns et al., 1998 [34] \\
\hline 105 & $t(5 ; 20)$ & $5 q 31 ; 20 p 13$ & Azoospermia & Poli et al., 2016 [18] \\
\hline 106 & $t(X ; 5)$ & Xp22.1;5p11 & Azoospermia & Peschka et al., 1999 [27] \\
\hline
\end{tabular}

\section{Cytogenetic analysis}

Cytogenetic analysis was carried out on all patients. Peripheral blood $(0.5 \mathrm{~mL})$ was collected in sterile tubes containing $30 \mathrm{U} / \mathrm{mL}$ heparin. Lymphocytes were then cultured in appropriate culture medium (Yishengjun; Guangzhou Baidi Biotech, Guangzhou, China) for $72 \mathrm{~h}$, and subsequently treated with $20 \mu \mathrm{g} / \mathrm{mL}$ colcemid for $1 \mathrm{~h}$. G-banding of metaphase chromosomes and karyotype analysis were performed using previously described methods [5]. Twenty metaphases were counted and 6 karyotypes were analyzed per patient. Karyotype nomenclature was described in accordance of ISCN2009. The resolution level of chromosome analysis was 400-550 band levels.

\section{Analysis of the identified translocation breakpoints}

A search of translocations identified in chromosome 5 from infertile males was performed using PubMed. The keywords "chromosome / translocation / sperm" and "chromosome / translocation / abortion" were used for the PubMed search. The relationships of translocation breakpoints with male infertility and recurrent pregnancy loss were analyzed. Such searches were performed for a total of 106 carriers of chromosomal 5 translocations. This study included the cases of reciprocal chromosomal translocations involving chromosome 5 in reported papers, and excluded cases without breakpoints, females, newborns, and bone marrow detection involving chromosome 5.

\section{Results}

A total of 82 translocation carriers were detected in this study. Of these, nine (11\%) were carriers of a chromosome 5 translocation, in which other chromosome abnormality had been excluded. Karyotype results and G-banding karyotypes from these nine patients are respectively summarized in Table 1 and Fig. 1. One case had azoospermia (pregestational infertility), while eight cases had normal semen. For the former, no AZF gene deletion was found. Of the later eight cases, it was evident that their partners were able to conceive, but had a tendency to miscarry (gestational infertility): three cases had experienced recurrent spontaneous abortions, two cases each experienced stillbirths, and three cases produced a phenotypically normal child confirmed by amniocentesis. For the other 73 cases of translocations, we will describe or have published in another study.

A literature review was also performed, from which karyotype results, clinical manifestations, and breakpoints on chromosome 5 were collected, as shown in Table 2. A total of 106 karyotypes included chromosome 5 translocations. The most common translocation was $\mathrm{t}(4 ; 5)$, observed in 13 patients, followed $\mathrm{t}(5 ; 8) \quad(N=11)$. Chromosomes $4(N=13), \quad 8(\mathrm{~N}=11), \quad 2,3,7,13(N=7)$, $1,9,10,12(N=6), 6,18(N=5), 15,20(N=4), 14,16,17(N=3)$ and $11,19, \mathrm{X}(\mathrm{N}=1)$ were respectively involved in the balanced translocation with chromosome 5 .

The most common breakpoint, at 5p15, was observed in 11 patients, followed by $5 q 13 \quad(N=10)$. 
Breakpoints at 5p14,5p11,5q13, 5q14, 5q15, 5q22, $5 q 31,5 q 35$ and $5 q 35.1$ were found with cases of both pregestational and gestational infertility. All breakpoints were associated with gestational infertility (Table 3).

\section{Discussion}

In clinical practice, male infertility can be broadly divided into two types of reproductive failure: pregestational and gestational infertility [16]. In the present

Table 3 Incidence of breakpoints on chromosome 5

\begin{tabular}{|c|c|c|}
\hline Breakpoints & $\begin{array}{l}\text { Number of patients with } \\
\text { pregestational infertility }\end{array}$ & $\begin{array}{l}\text { Number of patients with } \\
\text { gestational infertility }\end{array}$ \\
\hline$\overline{p 15.3}$ & & 1 \\
\hline p15.2 & & 3 \\
\hline p15.1 & & 4 \\
\hline p15 & & 11 \\
\hline p14 & 1 & 5 \\
\hline p13.3 & & 3 \\
\hline p13 & & 9 \\
\hline $\mathrm{p} 12$ & & 2 \\
\hline p11 & 1 & 2 \\
\hline$q 10$ & & 1 \\
\hline$q 11$ & & 3 \\
\hline q11.2 & & 2 \\
\hline$q 12$ & & 1 \\
\hline$q 13$ & 1 & 9 \\
\hline q13.1 & & 1 \\
\hline$q 13.2$ & & 1 \\
\hline q14 & 1 & 1 \\
\hline$q 15$ & 1 & 4 \\
\hline q21 & & 4 \\
\hline q22 & 2 & 3 \\
\hline q22.1 & & 1 \\
\hline q23.1 & & 1 \\
\hline q23.2 & & 1 \\
\hline q23.3 & & 1 \\
\hline q31 & 2 & 3 \\
\hline q31.1 & & 1 \\
\hline q33 & & 8 \\
\hline q33.1 & & 2 \\
\hline q33.2 & & 1 \\
\hline q33.3 & & 3 \\
\hline q34 & & 2 \\
\hline q35 & 1 & 6 \\
\hline q35.1 & 1 & 2 \\
\hline q35.3 & & 2 \\
\hline
\end{tabular}

study, nine of our cases were identified as carriers of chromosome 5 translocations, and we also reviewed 106 cases of chromosome 5 translocation reported in the literature. The breakpoints that we identified on chromosome 5 were found to be associated with pregestational or gestational infertility. One case was associated with pregestational infertility and eight cases were related to gestational infertility. Mikelsaar et al. [17] and Venkateshwari et al. [18] reported that the breakpoints at $5 \mathrm{q} 33$ and $5 \mathrm{q} 35$ in male carriers were associated with infertility. Kim et al. [19] reported that the breakpoint at 5p13 could interfere with spermatogenesis, and that breakpoints at $5 \mathrm{q} 15,5 \mathrm{q} 21.2,5 \mathrm{q} 22$ and $5 \mathrm{q} 32$ were related to recurrent abortion. To study the relationship of these breakpoints on chromosome 5 with male infertility, we analyzed recent published literature and revealed clinical features in carriers of chromosome 5 translocations. The karyotype results and clinical findings at chromosome 5 are summarized in Table 2. A common clinical feature associated with the breakpoints at 5p13, 5q33 and 5q35 was recurrent miscarriage, which was not consistent with the above reports.

Male infertility affects about $50 \%$ of couples unable to achieve pregnancy [20]. Chromosomal abnormalities are closely related to male infertility [21], and cytogenetic detection can provide valuable information for genetic counseling of infertile males [22]. Previous reports have shown that infertile men have an 8-10-fold higher prevalence of chromosomal abnormalities than fertile men [19]. Chromosomal translocation alters the complex and vital process of spermatogenesis, and leads to male infertility [20]. Chromosome 5 translocation has often been associated with male infertility or recurrent pregnancy loss $[17,18,23]$.

Table 3 shows that all breakpoints were associated with gestational infertility. These cases indicated that such breakpoints were not responsible for pregestational infertility, so another breakpoint of translocation must be responsible in these individuals. For instance, two individuals with the breakpoint $5 \mathrm{q} 22$ were associated with pregestational infertility, and exhibited clinical features of oligoasthenoteratozoospermia and asthenozoospermia (case 47 and 102, respectively, Table 2). The corresponding breakpoints of translocation in case 47 and 102 were 8q24.1 and 20p13, respectively. Kott et al. [24] reported that the primary ciliary dyskinesia-19 (CILD19) gene (OMIM: 614,935), mapped to chromosome 8q24, was associated with asthenospermia in infertile males. Previous studies have shown that the sperm flagellar protein 1 (SPEF1) gene (OMIM: 610,674) located on chromosome 20 p13 was be associated with curvature of microtubule bundles and the axoneme of sperm flagella [25]. Previous studies suggested that disruptions of CAMK4 located on chromosome 5q22.1, SPINK13 located on 
chromosome $5 \mathrm{q} 32$ and the testis-specific serine/threonine kinase $(T S S K 1 B)$ gene mapped to chromosome $5 q 22.2$ were associated with loss of sperm function and human male infertility $[8,9,26]$. In addition, the most common breakpoint, mapped to $5 \mathrm{p} 15$, was associated with gestational infertility. Other breakpoints were also identified as being associated with gestational infertility. For those affected by these breakpoints, natural conception remained possible with the potential to have normal children. For example, Ikuma et al. [4] reported that the live birth rate with natural conception for translocation carriers was $65 \%-83 \%$ cumulatively. However, natural conception has a greater risk. The number of chromosomal unbalanced gametes is large, leading to repetitive pregnancy loss, and may have repercussions on the fertility of translocation carriers. For these carriers, informed choice should be provided during genetic counseling.

The major limitation of our present study was the relatively small number of carriers of chromosome 5 translocations. Furthermore, we did not investigate the specific molecular effects of the translocations by molecular-cytogenetic methods.

\section{Conclusions}

In the present study, 115 carriers of chromosome 5 translocations were reviewed. The most common translocation and breakpoint were $t(4 ; 5)$ and $5 \mathrm{p} 15$, respectively. All breakpoints at chromosome 5 were associated with gestational infertility. In genetic counseling, physicians should consider chromosome 5 and its breakpoints. Carriers of chromosome 5 translocations maybe choose to continue with natural conception or use available assisted reproductive technologies, such as preimplantation genetic diagnosis.

\section{Abbreviations \\ AZF: Azoospermia factor; CAMK4: $\mathrm{Ca}^{2+} / \mathrm{calmodulin-dependent} \mathrm{protein} \mathrm{kinase}$ IV; CILD19: Ciliary dyskinesia-19; ISCN: International System for Human Cytogenetic Nomenclature; PGD: Preimplantation genetic diagnosis; SPEF1: Sperm flagellar protein 1; Spink13: Serine protease inhibitor, Kazal- type 13; TSSK1B: Testis-specific serine/threonine kinase}

\section{Acknowledgments}

We thank Charles Allan, PhD, from Liwen Bianji, Edanz Editing China (http://www.liwenbianji.cn), for editing the English text of a draft of this manuscript.

\section{Funding}

This work was supported by the Special Funds of Jilin Province Development and Reform Commission, China (2017C025).

\section{Availability of data and materials}

Data sharing not applicable to this article as no datasets were generated or analysed during the current study.

\section{Authors' contributions}

HGZ, LLL and HBZ performed the literature search, analyzed the data and wrote the manuscript. RXW, YP and HZ collected the clinical cases and patients. HGZ and RZL are responsible for the content and writing of the paper. All authors read and approved the final manuscript.

\section{Ethics approval and consent to participate}

The study protocol was approved by the Ethics Committee of the First Hospital of Jilin University, and written informed consent was obtained from all participants. (No.2010-082)

\section{Consent for publication}

Not applicable

\section{Competing interests}

The authors declare that they have no competing interests.

\section{Publisher's Note}

Springer Nature remains neutral with regard to jurisdictional claims in published maps and institutional affiliations.

Received: 14 November 2017 Accepted: 16 January 2018

Published online: 25 January 2018

\section{References}

1. Ventimiglia E, Capogrosso P, Boeri L, et al. When to perform karyotype analysis in infertile men? Validation of the European Association of Urology guidelines with the proposal of a new predictive model. Eur Urol. 2016:70:920-3.

2. Hotaling J, Carrell DT. Clinical genetic testing for male factor infertility: current applications and future directions. Andrology. 2014;2:339-50.

3. Song SH, Chiba K, Ramasamy R, et al. Recent advances in the genetics of testicular failure. Asian J Androl. 2016:18:350-5.

4. Ikuma S, Sato T, Sugiura-Ogasawara M, et al. Preimplantation genetic diagnosis and natural conception: a comparison of live birth rates in patients with recurrent pregnancy loss associated with translocation. PLoS One. 2015;10:e0129958.

5. Zhang HG, Wang RX, Li LL, et al. Male carriers of balanced reciprocal translocations in Northeast China: sperm count, reproductive performance, and genetic counseling. Genet Mol Res. 2015;14:18792-8.

6. Harton GL, Tempest HG. Chromosomal disorders and male infertility. Asian $J$ Androl. 2012;14:32-9.

7. Godo A, Blanco J, Vidal F, et al. Accumulation of numerical and structural chromosome imbalances in spermatozoa from reciprocal translocation carriers. Hum Reprod. 2013;28:840-9.

8. Wu JY, Ribar TJ, Cummings DE, et al. Spermiogenesis and exchange of basic nuclear proteins are impaired in male germ cells lacking Camk4. Nat Genet. 2000;25:448-52.

9. $\mathrm{Ma} \mathrm{L}, \mathrm{Yu} \mathrm{H}, \mathrm{Ni}$ Z, et al. Spink13, an epididymis-specific gene of the Kazaltype serine protease inhibitor (SPINK) family, is essential for the acrosomal integrity and male fertility. J Biol Chem. 2013;288:10154-65.

10. Kim JW, Chang EM, Song SH, et al. Complex chromosomal rearrangements in infertile males: complexity of rearrangement affects spermatogenesis. Fertil Steril. 2011;95:349-52. 352.e1-5

11. Vozdova M, Oracova E, Kasikova K, et al. Balanced chromosomal translocations in men: relationships among semen parameters, chromatin integrity, sperm meiotic segregation and aneuploidy. J Assist Reprod Genet. 2013;30:391-405.

12. Vloeberghs $V$, Verheyen $G$, Haentjens $P$, et al. How successful is TESE-ICSI in couples with non-obstructive azoospermia? Hum Reprod. 2015;30:1790-6.

13. De Krom G, Arens $\mathrm{YH}$, Coonen $\mathrm{E}$, et al. Recurrent miscarriage in translocation carriers: no differences in clinical characteristics between couples who accept and couples who decline PGD. Hum Reprod. 2015;30:484-9.

14. Franssen MT, Musters AM, van der Veen F, et al. Reproductive outcome after PGD in couples with recurrent miscarriage carrying a structural chromosome abnormality: a systematic review. Hum Reprod Update. 2011: 17:467-75.

15. Ozawa N, Maruyama T, Nagashima T, et al. Pregnancy outcomes of reciprocal translocation carriers who have a history of repeated pregnancy loss. Fertil Steril. 2008;90:1301-4.

16. Li D, Zhang $H$, Wang $R$, et al. Chromosomal abnormalities in men with pregestational and gestational infertility in northeast China. J Assist Reprod Genet. 2012;29:829-36.

17. Mikelsaar $\mathrm{R}$, Nelis $\mathrm{M}$, Kurg $\mathrm{A}$, et al. Balanced reciprocal translocation $\mathrm{t}(5$; 13)(q33;q12) and 9q31.1 microduplication in a man suffering from infertility and pollinosis. J Appl Genet. 2012;53:93-7.

18. Venkateshwari A, Srilekha A, Begum A, et al. De novo chromosomal translocation t(3;5)(q13;q35) in an infertile man. Andrologia. 2011;43:428-30. 
19. RI ML, O'Bryan MK. Clinical Review\#: State of the art for genetic testing of infertile men. J Clin Endocrinol Metab. 2010;95:1013-24.

20. Stouffs K, Seneca S, Lissens W. Genetic causes of male infertility. Ann Endocrinol (Paris). 2014;75:109-11.

21. Naasse $Y$, Charoute $H$, El Houate B, et al. Chromosomal abnormalities and $Y$ chromosome microdeletions in infertile men from Morocco. BMC Urol. 2015;15:95.

22. Poli MN, Miranda LA, Gil ED, et al. Male cytogenetic evaluation prior to assisted reproduction procedures performed in mar del Plata, Argentina. JBRA Assist Reprod. 2016;20:62-5.

23. Kochhar PK, Ghosh P. Reproductive outcome of couples with recurrent miscarriage and balanced chromosomal abnormalities. J Obstet Gynaecol Res. 2013;39:113-20.

24. Kott E, Duquesnoy P, Copin B, et al. Loss-of-function mutations in LRRC6, a gene essential for proper axonemal assembly of inner and outer dynein arms, cause primary ciliary dyskinesia. Am J Hum Genet. 2012;91:958-64.

25. Dougherty GW, Adler HJ, Rzadzinska A, et al. CLAMP, a novel microtubuleassociated protein with EB-type calponin homology. Cell Motil Cytoskeleton. 2005;62:141-56.

26. Hao Z, Jha KN, Kim YH, et al. Expression analysis of the human testis-specific serine/threonine kinase (TSSK) homologues. A TSSK member is present in the equatorial segment of human sperm. Mol Hum Reprod. 2004;10:433-44.

27. Peschka B, Leygraaf J, Van der Ven $\mathrm{K}$, et al. Type and frequency of chromosome aberrations in 781 couples undergoing intracytoplasmic sperm injection. Hum Reprod. 1999;14:2257-63.

28. Brugnon F, Van Assche E, Verheyen G, et al. Study of two markers of apoptosis and meiotic segregation in ejaculated sperm of chromosomal translocation carrier patients. Hum Reprod. 2006;21:685-93.

29. Meza-Espinoza JP, Anguiano LO, Rivera H. Chromosomal abnormalities in couples with reproductive disorders. Gynecol Obstet Investig. 2008;66:237-40.

30. Kyu Lim C, Hyun Jun J, Mi Min D, et al. Efficacy and clinical outcome of preimplantation genetic diagnosis using FISH for couples of reciprocal and Robertsonian translocations: the Korean experience. Prenat Diagn. 2004;24:556-61.

31. Goud TM, Mohammed Al Harassi S, Khalfan Al Salmani K, et al. Cytogenetic studies in couples with recurrent miscarriage in the Sultanate of Oman. Reprod BioMed Online. 2009:18:424-9.

32. Vegetti W, Van Assche E, Frias A, et al. Correlation between semen parameters and sperm aneuploidy rates investigated by fluorescence in-situ hybridization in infertile men. Hum Reprod. 2000;15:351-65.

33. Gada Saxena S, Desai K, Shewale L, et al. Chromosomal aberrations in 2000 couples of Indian ethnicity with reproductive failure. Reprod BioMed Online. 2012;25:209-18

34. Fryns JP, Buggenhout G. Structural chromosome rearrangements in couples with recurrent fetal wastage. Eur J Obstet Gynecol Reprod Biol. 1998:81:171-6.

35. Templado C, Navarro J, Benet J, et al. Human sperm chromosome studies in a reciprocal translocation t(2;5). Hum Genet. 1988;79:24-8

36. Portnoï MF, Joye N, van den Akker J, et al. Karyotypes of 1142 couples with recurrent abortion. Obstet Gynecol. 1988;72:31-4.

37. Adamoli A, Bernardi F, Chiaffoni G, et al. Reproductive failure and parental chromosome abnormalities. Hum Reprod. 1986;1:99-102.

38. Sugiura-Ogasawara M, Aoki K, Fujii T, et al. Subsequent pregnancy outcomes in recurrent miscarriage patients with a paternal or maternal carrier of a structural chromosome rearrangement. J Hum Genet. 2008:53:622-8.

39. Castle D, Bernstein R. Cytogenetic analysis of 688 couples experiencing multiple spontaneous abortions. Am J Med Genet. 1988:29:549-56.

40. Findikli N, Kahraman S, Kumtepe Y, et al. Embryo development characteristics in Robertsonian and reciprocal translocations: a comparison of results with non-translocation cases. Reprod BioMed Online. 2003;7:563-71.

41. Wiland E, Midro AT, Panasiuk B, et al. The analysis of meiotic segregation patterns and aneuploidy in the spermatozoa of father and son with translocation $t(4 ; 5)(\mathrm{p} 15.1 ; \mathrm{p} 12)$ and the prediction of the individual probability rate for unbalanced progeny at birth. J Androl. 2007;28:262-72.

42. Perrin A, Morel F, Douet-Guilbert N, et al. A study of meiotic segregation of chromosomes in spermatozoa of translocation carriers using fluorescent in situ hybridisation. Andrologia. 2010;42:27-34.

43. Pundir J, Magdalani L, El-Toukhy T. Outcome of preimplantation genetic diagnosis using FISH analysis for recurrent miscarriage in low-risk reciprocal translocation carriers. Eur J Obstet Gynecol Reprod Biol. 2016;203:214-9.

44. Zhang M, Fan HT, Zhang QS, et al. Genetic screening and evaluation for chromosomal abnormalities of infertile males in Jilin Province, China. Genet Mol Res. 2015;14:16178-84.
45. Ghazaey S, Keify F, Mirzaei F, et al. Chromosomal analysis of couples with repeated spontaneous abortions in northeastern iran. Int J Fertil Steril. 2015;9:47-54.

46. Zhang Z, Gao H, Li S, et al. Chromosomal abnormalities in patients with recurrent spontaneous abortions in northeast China. J Reprod Med. 2011;56:321-4.

47. Huang XF, Xiao SQ, Fei QJ, et al. Meiotic segregation results of male reciprocal chromosome translocations. Zhonghua Yi Xue Yi Chuan Xue Za Zhi. 2007;24:217-20.

48. Dohle GR, Halley DJ, Van Hemel JO, et al. Genetic risk factors in infertile men with severe oligozoospermia and azoospermia. Hum Reprod. 2002;17:13-6.

49. Dul EC, van Echten-Arends J, Groen H, et al. Chromosomal abnormalities in azoospermic and non-azoospermic infertile men: numbers needed to be screened to prevent adverse pregnancy outcomes. Hum Reprod. 2012;27:2850-6.

50. Dutta UR, Rajitha P, Pidugu VK, et al. Cytogenetic abnormalities in 1162 couples with recurrent miscarriages in southern region of India: report and review. J Assist Reprod Genet. 2011:28:145-9.

51. Kiss A, Rosa RF, Dibi RP, et al. chromosomal abnormalities in couples with history of recurrent abortion. Rev Bras Ginecol Obstet. 2009;31:68-74.

52. Ko DS, Cho JW, Park SY, et al. Clinical outcomes of preimplantation genetic diagnosis (PGD) and analysis of meiotic segregation modes in reciprocal translocation carriers. Am J Med Genet A. 2010;152A:1428-33.

53. Stephenson MD, Sierra S. Reproductive outcomes in recurrent pregnancy loss associated with a parental carrier of a structural chromosome rearrangement. Hum Reprod. 2006;21:1076-82.

54. Al-Hussain M, Al-Nuaim L, Abu Talib Z, et al. Cytogenetic study in cases with recurrent abortion in Saudi Arabia. Ann Saudi Med. 2000;20:233-6.

55. Estop AM, Van Kirk V, Cieply K. Segregation analysis of four translocations, $\mathrm{t}(2 ; 18), \mathrm{t}(3 ; 15), \mathrm{t}(5 ; 7)$, and $\mathrm{t}(10 ; 12)$, by sperm chromosome studies and a review of the literature. Cytogenet Cell Genet. 1995;70:80-7.

56. Cifuentes P, Navarro J, Blanco J, et al. Cytogenetic analysis of sperm chromosomes and sperm nuclei in a male heterozygous for a reciprocal translocation $t(5 ; 7)(q 21$; q32) by in situ hybridisation. Eur J Hum Genet. 1999;7:231-8.

57. Meschede D, Lemcke B, Exeler JR, et al. Chromosome abnormalities in 447 couples undergoing intracytoplasmic sperm injection-prevalence, types, sex distribution and reproductive relevance. Hum Reprod. 1998;13:576-82.

58. Blanco J, Egozcue J, Clusellas N, et al. FISH on sperm heads allows the analysis of chromosome segregation and interchromosomal effects in carriers of structural rearrangements: results in a translocation carrier, $t(5$; 8)(q33;q13). Cytogenet Cell Genet. 1998;83:275-80.

59. Estop AM, Cieply K, Munne S, et al. Is there an interchromosomal effect in reciprocal translocation carriers? Sperm FISH studies. Hum Genet. 2000;106:517-24.

60. Anton E, Vidal F, Blanco J. Reciprocal translocations: tracing their meiotic behavior. Genet Med. 2008;10:730-8.

61. Zhang Y, Zhu S, Wu J, et al. Quadrivalent asymmetry in reciprocal translocation carriers predicts meiotic segregation patterns in cleavage stage embryos. Reprod BioMed Online. 2014;29:490-8.

62. Rouen A, Carlier L, Heide S, et al. Potential selection of genetically balanced spermatozoa based on the hypo-osmotic swelling test in chromosomal rearrangement carriers. Reprod BioMed Online. 2017;35:372-8.

63. Iyer $\mathrm{P}$, Wani $\mathrm{L}$, Joshi $\mathrm{S}$, et al. Cytogenetic investigations in couples with repeated miscarriages and malformed children: report of a novel insertion. Reprod BioMed Online. 2007;14:314-21.

64. Bourrouillou G, Colombies P, Dastugue N. Chromosome studies in 2136 couples with spontaneous abortions. Hum Genet. 1986;74:399-401.

65. Ravel C, Chantot-Bastaraud S, Siffroi JP, et al. Tail stump syndrome associated with chromosomal translocation in two brothers attempting intracytoplasmic sperm injection. Fertil Steril. 2006;86(719):e1-7.

66. Goddijn $\mathrm{M}$, Joosten $\mathrm{JH}$, Knegt $\mathrm{AC}$, et al. Clinical relevance of diagnosing structural chromosome abnormalities in couples with repeated miscarriage. Hum Reprod. 2004;19:1013-7.

67. Zhang YP, Xu JZ, Yin M, et al. Pregnancy outcomes of 194 couples with balanced translocations. Zhonghua Fu Chan Ke Za Zhi. 2006:41:592-6.

68. Pellestor F, Sèle B, Jalbert H, Jalbert P. Direct Segregation analysis of reciprocal translocations: a study of 283 sperm karyotypes from four carriers. Am J Hum Genet. 1989:44:464-73.

69. Matsuda T, Horii Y, Ogura K, et al. Chromosomal survey of 1001 subfertile males: incidence and clinical features of males with chromosomal anomalies. Hinyokika Kiyo. 1992;38:803-9.

70. Escudero T, Abdelhadi I, Sandalinas M, et al. Predictive value of sperm fluorescence in situ hybridization analysis on the outcome of preimplantation genetic diagnosis for translocations. Fertil Steril. 2003; 79(Suppl 3):1528-34. 
71. Haapaniemi Kouru K, Malmgren H, White I, et al. Meiotic segregation analyses of reciprocal translocations in spermatozoa and embryos: no support for predictive value regarding PGD outcome. Reprod BioMed Online. 2017;34:645-52.

72. Mau UA, Bäckert IT, Kaiser $P$, et al. Chromosomal findings in 150 couples referred for genetic counselling prior to intracytoplasmic sperm injection. Hum Reprod1997; 12:930-937.

73. Balkan W, Martin RH. Chromosome segregation into the spermatozoa of two men heterozygous for different reciprocal translocations. Hum Genet. 1983;63:345-8.

74. Soh K, Yajima A, Ozawa N, et al. Chromosome analysis in couples with recurrent abortions. Tohoku J Exp Med. 1984;144:151-63.

75. Smith A, Gaha TJ. Data on families of chromosome translocation carriers ascertained because of habitual spontaneous abortion. Aust N Z J Obstet Gynaecol. 1990;30:57-62

Submit your next manuscript to BioMed Central and we will help you at every step:

- We accept pre-submission inquiries

- Our selector tool helps you to find the most relevant journal

- We provide round the clock customer support

- Convenient online submission

- Thorough peer review

- Inclusion in PubMed and all major indexing services

- Maximum visibility for your research

Submit your manuscript at www.biomedcentral.com/submit
Biomed Central 